\title{
BDHI: a French national database on historical floods
}

\author{
Michel Lang ${ }^{1, a}$, Denis Coeur ${ }^{2}$, Alexandre Audouard ${ }^{3,4}$, Marlène Villanova-Oliver ${ }^{3,4}$ and Jean-Philippe Pène $^{5}$ \\ ${ }^{1}$ Irstea, Hydrology-Hydraulics research unit, Villeurbanne, France \\ ${ }_{2}^{2}$ Acthys-Diffusion, Biviers, France \\ ${ }^{3}$ Univ. Grenoble Alpes, LIG, F-38000 Grenoble, France \\ ${ }^{4}$ CNRS, LIG, F-38000 Grenoble, France \\ ${ }^{5}$ MEEM/DGPR, La Défense, France
}

\begin{abstract}
The paper describes the various features of the BDHI database (objects, functions, content). This document database provides document sheets on historical floods from various sources: technical reports from water authorities, scientific accounts (meteorology, hydrology, hydraulics...), post-disaster reports, newspapers or book extracts... It is complemented by fact sheets on flood events, which provide a summary text on significant past floods: location, date and duration, type of flood, extent, probability, adverse consequences A search engine is provided for information search based on time (specific date or period), on location (district, basin, city) or thematic topic (document type, flood type, flood magnitude, flood impact...). We conclude by some future challenges in relation to the next cycle of the Floods Directive (2016-2022), with the inventory of past floods which had significant adverse impacts. What are the flood events that need to be integrated (new ones later than 2011 and/or previous floods that had not yet been selected)? How can the process of historical data integration be extended at a local scale, with an adequate process of validation? How to promote the use of BDHI database in relation with the development of the culture of risk?
\end{abstract}

\section{The Flood Directive}

Directive 2007/60/EC on the assessment and management of flood risks entered into force on 26 November 2007. Its aim is to reduce and manage the risks that floods pose to human health, the environment, cultural heritage and economic activity. The first 6-year cycle of the Floods Directive (2010-2015) has just been completed. All member states shall make available to the public the Preliminary Flood Risk Assessment (PFRA), the Flood Hazard and Risk Maps (FHRM) and the Flood Risk Management Plans (FRMP).

During the French PFRA, a set of 176 flood events has been selected by the French Ministry of Environment (MEEM) [1]. In 2011, it gave rise to a short description of the hydro meteorological conditions and the adverse consequences of each flood event into regional technical reports. It was followed in 2014 by the publication of a book [2] gathering all descriptive information with a set of maps and pictures illustrating the characteristics and the impacts of the flood events. In parallel, MEEM decided to launch a national database on historical floods (BDHI). This paper will present in section 2 the various features of the database and the related web application data (database structure, fact sheets on historical floods, query tools, content), as we will address in section 3 the main perspectives of improvement of knowledge on past floods during the second cycle of the Floods Directive (2016-2021).

\section{BDHI: a database and a web application}

In this section, we present the main features of the software solution we have developed for the BDHI project. The database relies on a relational model and is implemented using the Relational Database Management System Postgres, with its spatial extension PostGIS. A web application (http://bdhi.fr/) is built upon this database. Developed in PHP using the framework Symphony 2, it also relies on several web and GIS technologies (D3, Jquery, OpenLayers 2, Géoserver (SLD, WMS, WFS), etc. [3].

\subsection{Database structure}

The Database structure (figure 1) was designed around three main concepts: Document Sheet, Flood Sheet and Fact Sheet on a Flood Event. The first one refers to an original source document that describes one or several flood events (Table 1): identification information, a digital copy of the most relevant documents pages ${ }^{\mathrm{a}}$ and Meta information. It gives access to original source documents, with a first overall view on their content.

\footnotetext{
${ }^{\mathrm{a}}$ when possible in respect of ownership rights.
}

\footnotetext{
a Corresponding author: michel.lang@irstea.fr
} 
For each identified flood in a document, a so-called Flood Sheet has to be fulfilled (Table 2). It is based on the requested information on PFRA on significant past floods: location, date and duration, type of flood, extent, probability, adverse consequences on human health, economic activity, environment, and cultural heritage. Each Flood Sheet is associated with its source Document Sheet.

\begin{tabular}{|c|c|}
\hline \multirow{6}{*}{ Identification } & Title \\
\hline & Author \\
\hline & Date of publication \\
\hline & Conservation site \\
\hline & Type of document (printed, file, video) \\
\hline & Sponsor \\
\hline \multirow{3}{*}{ Digital copy } & Ownership rights \\
\hline & Web address \\
\hline & File \\
\hline \multirow{3}{*}{ Content } & $\begin{array}{l}\begin{array}{l}\text { Identified floods } \\
\text { location) }\end{array} \\
\end{array}$ \\
\hline & $\begin{array}{l}\text { Technical issues (hydrometeorological } \\
\text { data, map) }\end{array}$ \\
\hline & $\rightarrow$ List of flood sheets \\
\hline
\end{tabular}

Table 1. Structure of a Document sheet

\begin{tabular}{|c|c|}
\hline \multirow{2}{*}{ Identification } & Title \\
\hline & Source of document \\
\hline $\begin{array}{l}\text { Date or } \\
\text { period }\end{array}$ & $\begin{array}{l}\text { Precise or approximate (century, year, } \\
\text { season...) }\end{array}$ \\
\hline \multirow{4}{*}{$\begin{array}{l}\text { Location } \\
\text { (several } \\
\text { territorial } \\
\text { divisions) }\end{array}$} & $\begin{array}{l}\text { Flood Directive: district and territorial } \\
\text { unit }\end{array}$ \\
\hline & $\begin{array}{l}\text { French DB Carthage } \mathbb{R}^{b} \text { : river basins and } \\
\text { sub-basins }\end{array}$ \\
\hline & $\begin{array}{l}\text { French administrative division: county } \\
\text { and town }\end{array}$ \\
\hline & Maritime units (12 units) \\
\hline Flood type & $\begin{array}{l}6 \text { main types: river flood, water runoff, } \\
\text { coastal flood, rising groundwater, dam } \\
\text { failure or dyke breaching, glacier- } \\
\text { outburst flood }\end{array}$ \\
\hline \multirow{5}{*}{ Flood hazard } & Meteorological data \\
\hline & Hydrological data \\
\hline & Tidal data \\
\hline & Flooded area \\
\hline & $\begin{array}{l}\text { Related natural hazards: landslide, } \\
\text { logjam, storm... }\end{array}$ \\
\hline \multirow[b]{3}{*}{ Flood impact } & Casualties \\
\hline & Total damages \\
\hline & $\begin{array}{l}\text { Eventually more focussed information: } \\
\text { economic activity, buildings and public } \\
\text { services, private property, transport } \\
\text { infrastructure, flood defences, water- } \\
\text { energy-telecommunication networks }\end{array}$ \\
\hline \multirow{5}{*}{$\begin{array}{c}\text { Flood } \\
\text { management }\end{array}$} & Forecasting and warning \\
\hline & Crisis management \\
\hline & Feedback report \\
\hline & Natural disaster declaration \\
\hline & Repair and reconstruction \\
\hline
\end{tabular}

Table 2. Structure of a Flood sheet

\footnotetext{
${ }^{\mathrm{b}}$ http://professionnels.ign.fr/bdcarthage
}

\begin{tabular}{|c|c|}
\hline \multirow{3}{*}{ Identification } & Title \\
\hline & Author \\
\hline & $\rightarrow$ List of selected flood sheets \\
\hline Date or period & \multirow{6}{*}{$\begin{array}{c}\text { Same structure than a Flood } \\
\text { Sheet }\end{array}$} \\
\hline Location & \\
\hline Flood type & \\
\hline Flood hazard & \\
\hline Flood impact & \\
\hline Flood management & \\
\hline $\begin{array}{c}\text { Diagrams- } \\
\text { Photographs- } \\
\text { Drawings }\end{array}$ & $\begin{array}{l}\text { Supplementary to the previous } \\
\text { information }\end{array}$ \\
\hline WMS link & Towards another database \\
\hline
\end{tabular}

Table 3. Structure of a Fact sheet on a Flood event

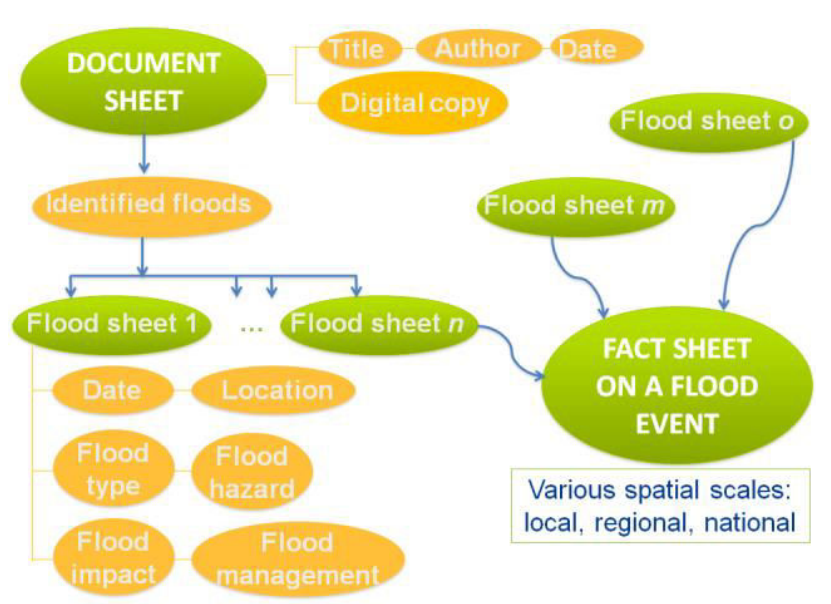

Figure 1. Representation of the BDHI database structure.

The third concept of the BDHI database is the Fact Sheet on a flood event (Table 3). It aims at providing a full description of a flood event, as described in several documents that offer possibly different points of view on the event or pieces of information about it. This reflects the present knowledge on past flood according to the available information in documents. A Fact Sheet is globally structured as a Flood Sheet is: it encompasses the same fields to be fulfilled, plus some specific fields for synthesis purpose.

We explain in the next section the process that leads to the data creation into the BHDI Database.

\subsection{From Documents to Fact sheets on historical floods}

The filling of the BDHI database shall follow several steps. Firstly, it is necessary to collect flood information from several medias (technical reports or databases, newspapers, web documentary search tools...) on various items (meteorology-hydrology-hydraulics reports, regulatory documents on flood risk, field reports on flood consequences - flood repairs...). An initial short listing based on the most interesting documents allows focusing on a limited number of flood events and flood documents. A Document Sheet is completed for each document, and the corresponding Flood Sheets are created and fulfilled as precisely as possible. 
Secondly, different pieces of information are put together, with a cross-checking and analysis work. The BDHI application allows selecting all the Flood Sheets corresponding to a specific query on a flood event (e.g. based on the date and the location). Information from the relevant Flood Sheets is therefore automatically reported within the descriptive items of the Fact Sheet on the flood event. As the structures of the Flood Sheet and the Fact Sheet on the flood event are similar, the remaining work is to validate information and eventually summarize or make a decision in case of inconsistent data.

Thirdly, a regional revision committee checks the final description of each flood event before making it become freely available on the web site http://bdhi.fr/.

\subsection{Query and visualisation tools}

All flood information is accessible by simple or advanced queries, or using a spatio-temporal explorer. A simple query on a Document Sheet refers to a limited numbers of attributes: Date, Title, Author, Flood Period, Location (either with a Flood Directive or an Administrative spatial division), or Sheet's ID. Additional attributes can be used: Location (with river basin division or maritime units), Document Sheet's Author, Type of Document, Type of content, and availability of a digital copy.

A simple query on a Flood Sheet or a Fact Sheet on the flood event refers to the following attributes: Flood Period, Location (either with a Flood Directive or an Administrative spatial division), Flood type (6 items), or Sheet's ID. Additional attributes can be used: Sheet's Author, Location (with river basin division or maritime units), Flood characteristics (duration, flood type -22 items, related natural hazards, availability of flooded area, natural disaster declaration), Hydro meteorological threshold exceedance (rainfall, discharge, tide...), and the Flood impacts (number of deaths, amount of damages, impacts on environment or cultural heritage).

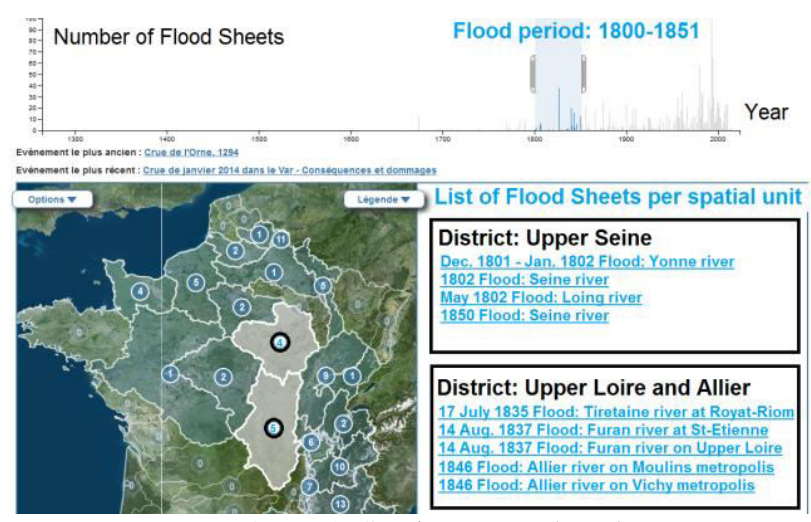

Figure 2. Spatio-temporal explorer

Figure 2 gives an example of the spatio-temporal explorer, with three dynamic and synchronized components: at the top a temporal window, with the reported number of flood sheets (here we focus on the period 1800-1851); at the bottom left a spatial window (two possible map displays: satellite picture or topographic map) showing the different spatial units that have Flood Sheets associated for the considered period (the two spatial units the user chooses to explore are highlighted); and at the bottom right are listed the Flood sheets that match the spatio-temporal request. Each Flood Sheet is reachable by a hyperlink.

It is possible to produce automatically a map of the approximate spatial extent of a set of flood events, by selecting a spatial unit and a list of flood events. It is based on a specific mapping methodology developed by [4], which aim is to provide a readable map on spatiotemporal and thematic information. Figure 3 shows an example on the upper Loire and Allier basins, with 7 flood events (January 1789, November 1790, July 1835, August 1837, September 1900, January 1982, November 1994). Such map can be downloaded on pdf or shp formats.

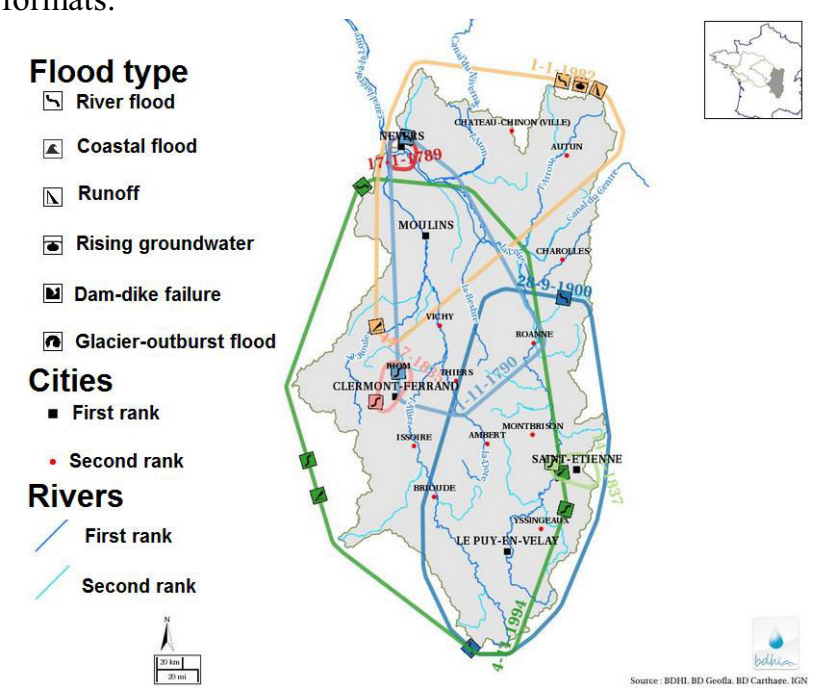

Figure 3. Map of the approximate spatial extent of 7 flood events on the upper Loire and Allier basins

\subsection{Database content}

On 1st January 2016, the content of the BDHI database was the following: 106 Fact Sheets on flood events, 1076 Document Sheets and 1382 Flood Sheets. By the end of 2016, public will have a free access to the Fact Sheets of the 176 flood events that have been selected during the PFRA2011.

The selected events are issued from the period 1770 2011, but with an unequal distribution: 14 flood events before 1850, 36 before 1900, 59 before 1950, 84 before 1980 and more than half after 1980. Of course, it does not mean that the number of flood events is increasing, but rather that we have chosen more recent events, as easier to put in the actual context of stake and vulnerability.

However, some extreme past events remain a reference, as they could have today huge social and economic impacts. The most striking example is the 1910 flood event in Paris (100 year return period), responsible for economic loss estimated at around EUR 1.5 billion [5]. Today, this flood could generate a loss of EUR 30 billion [6] according to the current land use in Paris metropolis. Even if the comparison between flood damages remains difficult as the framework is rarely identical (assessment based on loss or compensation, 
rough or detailed reports), one of the main lesson is that the flood damages are clearly increasing.

Table 4 reports the eight flood events since 1910 corresponding to damages exceeding a threshold of EUR 1 billion. All events are arising from the last two decades, except the 1910 flood and the 1958 flood events. Such damaging could either be related to flash floods or slow on-set floods.

\begin{tabular}{|c|c|c|}
\hline Flood event & $\begin{array}{c}\text { Flood } \\
\text { type }\end{array}$ & $\begin{array}{c}\text { Damages } \\
\text { (EUR billion) }\end{array}$ \\
\hline November 1999, Aude basin & FF & 3.5 \\
\hline February 2010, Xynthia & Storm & 2.5 \\
\hline January 1910, Seine basin & SF & 1.6 \\
\hline $\begin{array}{c}\text { September 2002 } \\
\text { Gardon \& Cèze basins }\end{array}$ & FF & 1.4 \\
\hline $\begin{array}{c}\text { Sept. Oct. 1958 } \\
\text { Gardon \& Cèze basins }\end{array}$ & FF & 1.4 \\
\hline December 2003, Rhône river & SF & 1.1 \\
\hline $\begin{array}{c}\text { June 2010 } \\
\text { Argens \& Nartuby basins }\end{array}$ & FF & 1.0 \\
\hline 2000-2001 winter, Brittany & SF & 1.0 \\
\hline
\end{tabular}

Table 4. Catastrophic floods with more than EUR 1 billion (FF: Flash Floods; SF: Slow Floods)

The most catastrophic flood events over the two past centuries with more than 100 fatalities (see table 2) are all issued from severe floods with strong impact forces: cyclones, dam failure, glacier-outburst flood or flash flood. The fact that they are not modern events (prior to 1960) reflects the current state of progress being made in forecasting, warning and rescuing population. But some recent events like flash floods (September 1992 flood on Ouvèze river, 41 deaths; November 1999 flood on Aude river, 35 deaths) or storms (February 2010, Xynthia, 53 deaths) remind us that rapid overflowing of protective structures can still have strong impacts.

\begin{tabular}{|c|c|c|}
\hline Flood event & Flood type & Deaths \\
\hline $\begin{array}{c}\text { Sept. 1928 } \\
\text { Guadeloupe Island }\end{array}$ & Cyclone & 1200 \\
\hline June 1875, Garonne basin & Flash flood & 500 \\
\hline December 1959, Malpasset & Dam breaking & 423 \\
\hline $\begin{array}{c}\text { March 1930 } \\
\text { Tarn \& Garonne basins }\end{array}$ & Flash flood & 230 \\
\hline July 1892, Saint-Gervais & $\begin{array}{c}\text { Glacier- } \\
\text { outburst flood }\end{array}$ & 175 \\
\hline $\begin{array}{c}\text { January 1948 } \\
\text { Réunion Island }\end{array}$ & Cyclone & 165 \\
\hline $\begin{array}{c}\text { Sept. 1875 } \\
\text { Orb \& Vernazobre basins }\end{array}$ & Flash flood & 125 \\
\hline
\end{tabular}

Table 5. Catastrophic floods with more than 100 deaths

\section{Prospects for an improved knowledge on past floods}

\subsection{Flood events to be integrated}

During the first cycle of the Floods Directive, the French authorities made a selection of 176 flood events from the period 1770-2010, by means of consultation with local risk managers. Several criteria were used: intense event based on flood magnitude and/or spatial extent, diversity of flood typology, economic and social impacts, design event from flood zoning, last major event in memory, etc. The question remains open as to which flood events need to be integrated during the second cycle of the Floods Directive (2016-2021). Some recent flood events (post 2011) or new "old" flood events (prior to 2011) may be selected, in addition to existing PFRA2011 flood events (some of them may be now better documented).

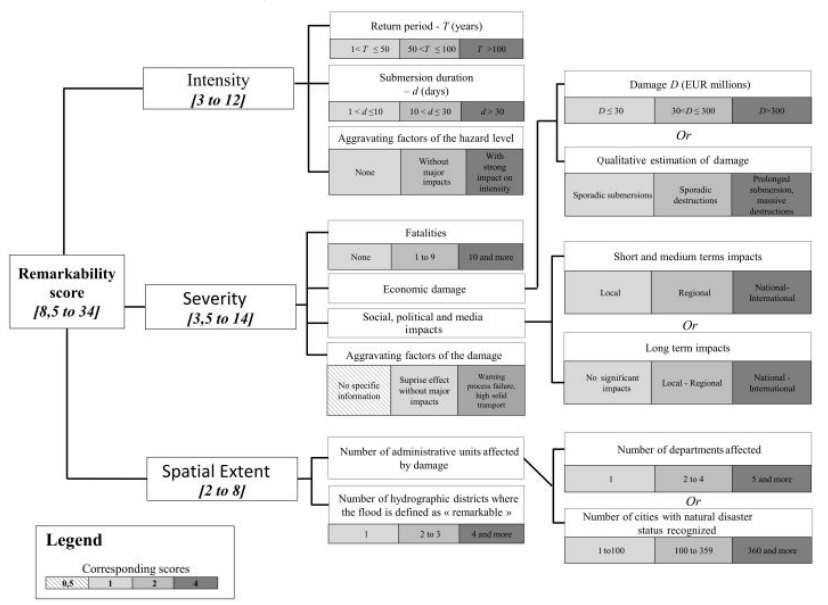

Figure 4. Evaluation grid of "remarkable" flood events

Figure 4 presents an evaluation grid developed and used by [5] and [7], with the aim of selecting the most "remarkable" events amongst the list of 176 PFRA2011 flood events. This grid is based on three main features: 1/ flood intensity; 2/ flood severity; 3/ spatial extent of flood. It may help to choose from a large list of eligible flood events.

\subsection{Process for historical data integration and validation}

One of the future challenges is an efficient updating of the BDHI database, involving a large panel of flood experts. During the first cycle of the Floods Directive, data collection on historical floods was concentrated over a short period of six months (from March to July 2011) with the contribution of seven non-permanent staff and a review by regional authorities. The aim is now to enlarge the contributions of local authorities or communities, and to establish regional committees in charge of data validation. In 2014-2015, a set of pilot actions have been launched at a local scale. Some examples are the digitization of old maps related to river works on alpine rivers in Southern Alps, or the filling of four flood events (October 1966, November 1974, January 1995, January 
2001) on Vilaine basin in Brittany based on a more complete documentation. In 2016, some special training days are scheduled for regional authorities in charge of flood risk. They are expected to be able to integrate independently or through technical subcontractors new data within the BDHI database, and to provide a final validation through experts (see Figure 5). The goal is to implement an operational system that will be able to integrate past events and recent flood events. It will be able to manage data quality, to operate at several geographic scales (local, regional), and to propose a strategy of feedback on flood events.

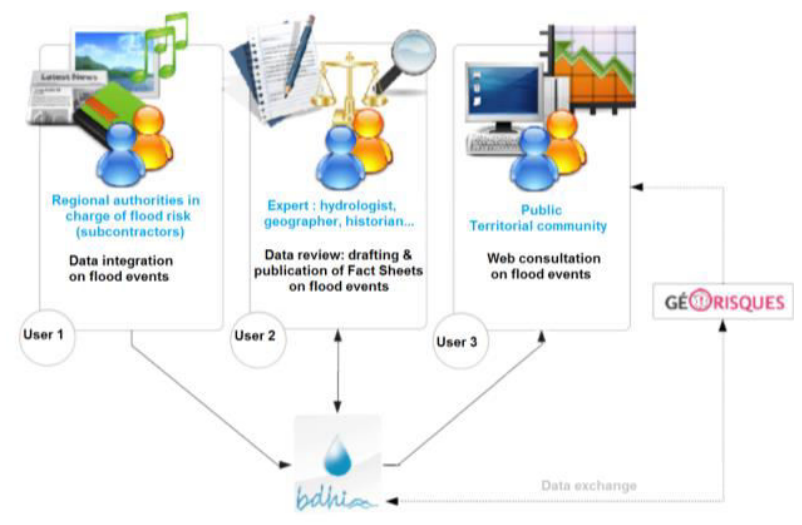

Figure 5. Various users of the BDHI database

\subsection{Link with other databases}

Obviously, information on flood risk is not limited to a unique database. A national Internet portal is managed by MEEM to inform the public about the prevention of natural and technological risks (http://www.prim.net/). It has been complemented by a new internet portal (http://www.georisques.gouv.fr/), which provides for example detailed information on risk at the local authority level ("what is the risk in my town-village?"). A specific heading has been added which provides a dynamic reporting of the flood events within the townvillage, as available within the BDHI database ${ }^{c}$. It means that such reporting is updated whenever new information is added into the BDHI database. When no flood event is registered within the town-village, available information is displayed at a larger spatial scale (neighbouring communities or county).

MétéoFrance has developed a web site on extreme rainfall in France (http://pluiesextremes.meteo.fr/). A list of 320 remarkable rainfall events is available in mainland France (from August 1773 to February 2015), supplemented by 43 remarkable rainfall events in overseas departments (from 1967 to 2014). In 2016, a dynamic reporting is studied to provide a link to the corresponding fact sheet whenever an extreme rainfall event has been reported as a flood event within the BDHI database.

A third web site will be launched by MEEM in 2016, devoted to the inventory of flood marks in France. The database will provide information on several thousand flood marks: location (county, city, river), water mark

\footnotetext{
${ }^{\mathrm{c}}$ OGC Web Services have been developed for that purpose
}

(type of mark, quality), flood event (date, type of flood, return period), altitude (water level, levelling system), pictures and documentary sources. It will be interesting to connect this new web site with the BDHI database, having whenever possible additional information to the corresponding fact sheet on the flood event. Conversely, a fact sheet of the BDHI database may content a list of the available flood marks.

\section{4 $\mathrm{BDHI}$ and the development of the culture of risk}

Culture of risk is one of the basic tools for reducing the impact of flood risk. It may be based on websites or leaflets which explain how to cope with a flood emergency or how to reduce its vulnerability. It may be possible to give some testimonies on the consequences of past floods through memorial events (e.g. the 100-year anniversary of the 1910 flood in Paris), memorial sites and flood marks, films, websites, plays, books, leaflets...

The BDHI database gives several opportunities to improve the development of the culture of flood risk. It is a central place at a national level, where flood information can be uploaded and shared. It could help to move on from short to medium - long term memory. BDHI database, as a technical tool, could be complemented by more applied web sites, devoted to the communication of flood risk to public at a local scale (city or river basin).

\section{Conclusion}

The first cycle of the Floods Directive (2010-2015) gave the opportunity to gather at national scale flood information on past floods. Such information can be used to improve the knowledge on flood risk and to reduce the potential adverse consequences on future floods. The BDHI database is an efficient tool for data collection, exploration and exchange. What has been learned in the process of developing the BDHI is the difficulty to build a coherent and detailed database at a national scale. It is important to invest time and energy in data collection and review. Over the next years, the main challenges will be to implement a process for enlarging the contributions to the main stakeholders with flood knowledge, and to improve the connexions between the various websites providing flood information to public. It is intended to develop a common base of knowledge on past floods, which can be used for flood risk reduction both from a technical perspective (flood hazard maps, flood protection, flood forecasting) and social engagement (knowledge building, reduction of vulnerability).

\section{References}

1. Lang M., Coeur C., Bard A., Becker T., Bignon E., Blanchard R., Bruckmann L., Delserieys M., Edelblutte C. and Merle C. (2012). Preliminary Flood Risk Assessment for the European Directive: inventory of French past floods. In "Comprehensive Flood Risk Management”, Kjlin \& Schweckendiek 
Ed., Taylor and Francis Group, London, ISBN 9780-415-62144-1, 1211-1217

2. Lang M. and Coeur D. (2014). Les inondations remarquables en France. Inventaire 2011 pour la directive Inondation, Ed. Quae, 640p.

3. Cœur D, Lang M, Villanova-Oliver M., Hombiat A., Saint-Marc C., Davoine P.A., Gensel J., Audouard A. and Blanchard R. (2015). BDHI Capitalisation de l'information géo-historique dans le cadre de la Directive Inondation. Festival International de Cartographie, Saint-Dié des Vosges, 2-4 oct. 2015.

4. Saint-Marc C., Davoine P.A., Villanova-Oliver M., Lang M. and Cour D. (2015). Cartographie des inondations historiques majeures superposées sur un territoire. Cartes et Géomatique, 27ème conférence cartographique internationale, 226, 127-134.

5. Boudou M. (2015). Approche multidisciplinaire pour la caractérisation d'inondations remarquables : enseignements tirés de neuf évènements en France (1910-2010). PhD, Irstea - Lyon, Univ. Montpellier III, Montpellier, 463 p. +450 p. (appendix).

6. OCDE (2014). Etude l'OCDE sur la gestion des risques d'inondation: la Seine en Ile-de-France 2014. OECD, 2014, 214p.

http://www.seinegrandslacs.fr/etude-ocde

7. Boudou M., Lang M., Vinet F. and Cœur D. (2016). Comparative hazard analysis of processes leading to four remarkable flash floods (France, 1930-1999). $J$ Hydrology, in press. 